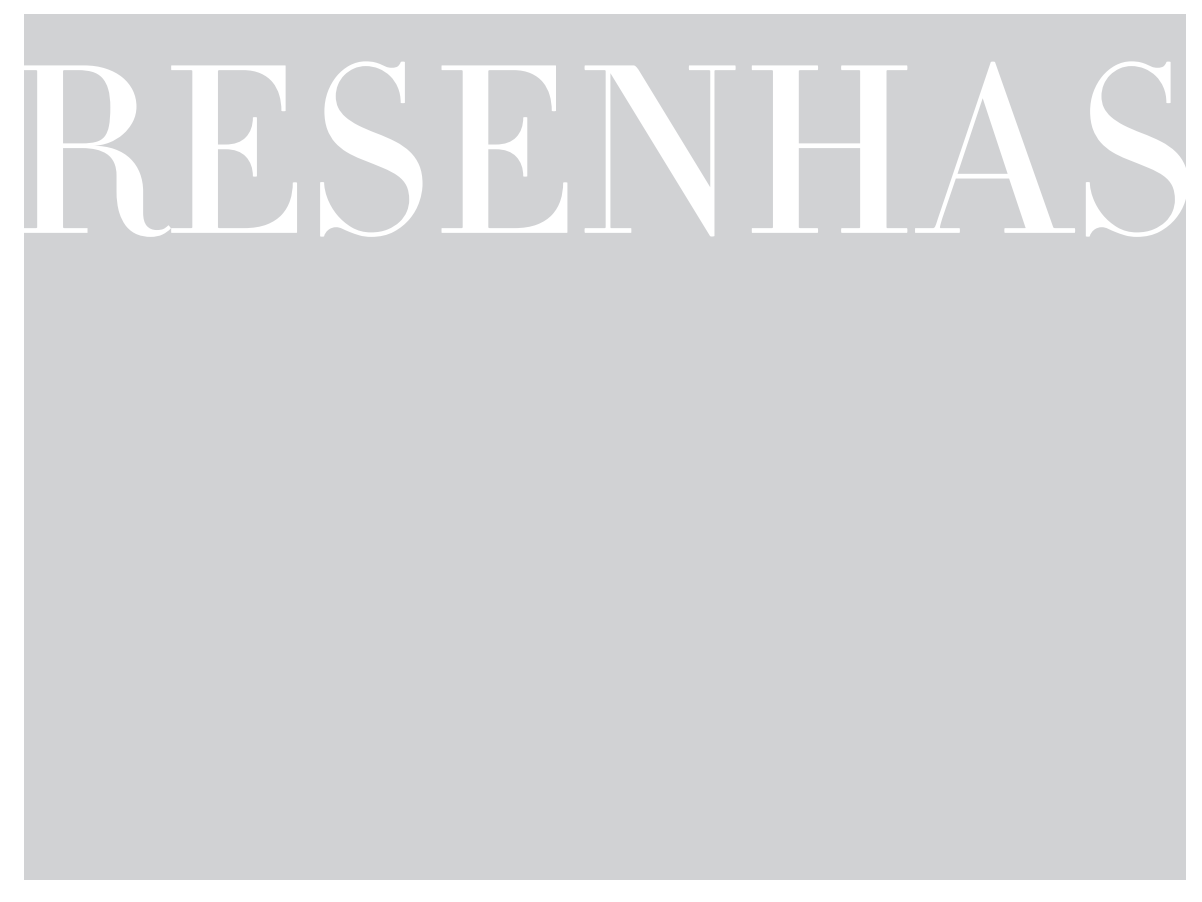

\title{
GÊNERO, TRABALHO E CUIDADO: CONTINUIDADES E DESCONTINUIDADES
}

http://dx.doi.org/10.1590/198053144415

ABREU, Alice Rangel de Paiva; HIRATA, Helena; LOMBARDI, Maria Rosa (Org.). Gênero e trabalho no Brasil e na França: perspectivas interseccionais. São Paulo: Boitempo, 2016.

O livro Gênero e trabalho no Brasil e na França: perspectivas interseccionais, organizado por Alice Rangel de Paiva Abreu, Helena Hirata e Maria Rosa Lombardi, é fruto das discussões desenvolvidas no Colóquio Internacional Trabalho, cuidado e políticas sociais: Brasil-França em debate, realizado no Brasil em agosto de 2014. O evento fez parte de um intercâmbio de longo prazo entre pesquisadores/as brasileiros/as de diversas instituições científicas do país e membros da Rede Marché du Travail et Genre - MAGE - da França. A publicação registra o aprofundamento da reflexão dos autores sobre o trabalho e o gênero, em que se fazem presentes a noção do care e as perspectivas interseccionais, entre outras. Não se faz uma comparação sistemática entre os dois países, mas colocam-se em diálogo contextos e análises que interagem por suas afinidades temáticas, metodológicas e conceituais. Assim, o livro conta com 23 capítulos escritos por 28 autores/as e é organizado em seis partes: Entrecruzar as desigualdades; Medir as desigualdades; Trabalho e uso do tempo; O gênero das carreiras artísticas e científicas; Cuidado, dinâmicas familiares e profissionais; e Cuidado, políticas sociais e cidadania.

A discussão sobre gênero e trabalho na sociologia brasileira acumula um percurso que supera meio século. Nos anos 1970, autoras como Heleieth Saffioti (1976) e Eva Blay (1978) tornaram públicas 
algumas das primeiras pesquisas que adotavam a mulher como objeto de análise, tendo como referência a sua inserção no mundo do trabalho, ainda de modo marginal. Mas foi nos anos 1980-1990 que os estudos sobre mulher, gênero e trabalho se institucionalizaram, ${ }^{1}$ por meio da participação das estudiosas/os nos congressos científicos mais importantes, como nos da Associação Nacional de Pós-Graduação em Ciências Sociais - Anpocs -, da criação de núcleos de pesquisa e de revistas especializadas (CASTRO, 1992; CASTRO; LAVINAS, 1992; HEILBORN; SORJ, 1999). A categoria gênero foi definitivamente adotada e a divisão sexual do trabalho tornou-se uma das matrizes paradigmáticas na compreensão do sentido do trabalho para as mulheres no capitalismo (CASTRO, 1992). ${ }^{2}$ O massivo e variado ingresso da mão de obra feminina na indústria e nos serviços fez surgir a necessidade de introduzir críticas às análises nas quais se homogeneizava a vivência de homens e mulheres no contexto produtivo (SOUZA-LOBO, 2011). A tendência foi acompanhada de aumento do nível de educação das mulheres, da não interrupção das atividades profissionais apesar da maternidade, assim como da presença de trabalhadoras mais velhas (BRUSCHINI, 2007). A participação das mulheres no mercado não garantiu, contudo, uma inserção de qualidade para a maioria delas, as quais foram também as mais atingidas pelo desemprego (BRUSCHINI, 2007). A classe social, a etnicidade, o ciclo de vida e a posição na família constituíram-se em instrumentos analíticos para compreender as especificidades da inserção da mulher na esfera produtiva (CASTRO, 1992; CASTRO; LAVINAS, 1992).

Os artigos reunidos nessa coletânea discutem temas cruciais das relações de gênero no trabalho e se desenvolvem em torno do paradigma do care de modo a enfrentar sua complexidade, avançando para além do trabalho. Pontuo a seguir os principais.

\section{O TRABALHO FEMININO: CONTINUIDADES E DESCONTINUIDADES}

Um olhar sobre as continuidades e descontinuidades a respeito dos temas clássicos tratados na sociologia do gênero e trabalho faz constatar que as desigualdades sociais persistem no Brasil e na França apesar do vertiginoso avanço das mulheres na educação nas últimas décadas. Embora se esperasse que, após quarenta anos de inserção massiva da força de trabalho feminina no mercado moderno, passando pelo movimento feminista e a introdução de políticas públicas, as desigualdades pudessem ter sido verdadeiramente estreitadas, algumas análises apontam para resultados contrários, seja em termos de caracterização do trabalho feminino e sua quantificação na França e no Brasil - como apontam a pesquisa de Maruani e Meron e estudo de Guimarães e Marschner -; em termos salariais e de carreira, aspectos abordados por Silvera; de formalização do trabalho (ver estudo de Lavinas, Cordilha

É importante registrar que a inserção dos estudos sobre mulher e gênero na academia foi uma conquista concomitante às conquistas resultantes do movimento feminista (COSTA; BARROSO; SARTI, 1985).

2

O conceito de divisão sexual do trabalho tem sua origem na concepção marxiana da divisão social do trabalho, a qual foi retomada por autoras como Helena Hirata e Danièle Kergoat para explicar uma distribuição diferenciada e desigual de trabalho entre os sexos (2007). Tratar a divisão sexual do trabalho significava não apenas denunciar as desigualdades entre homens e mulheres, mas também desconstruir a noção clássica do trabalho e tratar as atividades domésticas em articulação com a produção (HIRATA; KERGOAT, 2007). 
e Cruz); das desvantagens em termos de uso e abuso do tempo das mulheres latino-americanas, como abordado por Abramo e Valenzuela e também por D’Ávila; e de visibilidade das desvantagens das mulheres nas categorizações desemprego e inatividade, conforme verificou Meron.

Os textos de modo geral apontam para o fato de que as desvantagens femininas no mercado de trabalho só podem ser entendidas por meio de uma análise de gênero interseccionada com classe, raça/etnia/nacionalidade e geração. ${ }^{3}$ Porém, permanece subjacente uma tensão entre o uso desse conceito com o da consubstancialidade, tendo como referência o posicionamento de Kergoat (2016) a favor deste último por privilegiar a análise em termos de relações sociais. O livro carece de uma manifestação com mais destaque sobre a interseccionalidade mencionada no título, apesar da ausência de consenso sobre o uso do conceito.

Os estudos sobre o trabalho feminino desvantajoso, recentemente intensificados pelo olhar voltado para o contexto da globalização neoliberal - e os desafios da democracia -, trazem a novidade da ambivalência dessa atividade, centralmente vinculada ao care (Ávila, Falquet, Hirata, Kergoat, Piscitelli, Jany-Catrice). De um lado, mostram o quanto se reproduzem e se intensificam as desiguais relações de gênero, classe, raça/etnia/nacionalidade. Trata-se de nichos tipicamente ocupados pelas mulheres, nos quais a concorrência ocorre entre elas, cada qual mobilizando seu capital afetivo, social e simbólico (Hirata, Piscitelli) em um amplo mercado nacional e internacional formado por cuidadoras, empregadas domésticas, babás e profissionais do sexo (HOCHSCHILD; EHRENREICH, 2004). De outro, o care firma-se como um lugar onde se experimenta o agenciamento das mulheres desfavorecidas que encontram no trabalho do cuidado oportunidades de autonomia econômica, entre outras, e a consequente emancipação (Ávila, Falquet, Kergoat).

O processo de empoderamento por meio do trabalho é igualmente demonstrado em contextos em que as mulheres devem desafiar as fronteiras de gênero, classe e raça/etnia/nacionalidade tradicionalmente traçadas. As resistências contra o avanço profissional das mulheres são fortes

Tal perspectiva foi teorizada por Kimberlé Crenshaw, feminista negra norteamericana que abordou a complexa questão do sistema de discriminação das mulheres negras no mercado de trabalho (1989) bem como sua condição de vítimas de violência - no âmbito doméstico como em espaços públicos (1991). A autora argumenta que, quando se oculta a dimensão racial no estudo sobre a desigualdade entre os sexos, invisibiliza-se a discriminação específica contra as mulheres negras (CRENSHAW, 1989). quando estas se engajam em carreiras de prestígio tradicionalmente masculinas, como a carreira científica (Abreu, Oliveira, Vieira e Marcondes), a da engenharia e da aviação (Lombardi, Gonzalez; Lapeye) e artísticas, como em orquestras (Segnini). Tais profissões requerem uma formação superior e/ou especializada em áreas tipicamente ocupadas por homens brancos de classe média. Enquanto outsiders nesse meio de carreira de prestígio, as mulheres encontram resistência e pressão por parte dos “estabelecidos" (ELIAS; SCOTSON, 2000). Para fazer face à "sociodinâmica da exclusão” (ELIAS; SCOTSON, 2000), umas contam com o apoio familiar, inclusive em termos financeiros (Segnini), o que faz sobressair a dimensão de classe. Outras se engajam em mobilizações coletivas e participam de políticas públicas de incentivo à mixidade (Lombardi e Gonzalez; Lapeye). 


\section{CARE E SUAS IMPLICAÇÕES SUBJETIVAS E POLÍTICAS}

O conjunto dos escritos de Arango, Damamme, Hirata e Soares mostra que o care é uma atividade por meio do qual os sujeitos, profissionais ou familiares, frequentemente em condições precárias, devem ajudar a tornar efetiva a vida cotidiana das pessoas em situação de vulnerabilidade e dependência, assim como a superarem sofrimentos e a se realizarem. Trata-se de uma construção interativa com os/as destinatário/as do cuidado que se faz dentro de variados aspectos típicos dessa atividade como a grande concentração de mulheres, cujo trabalho é pouco valorizado, marcado pela assimetria de poder atravessada pelas dimensões de classe, raça/etnia/nacionalidade e geração. Muitas vezes executado em espaços privados domiciliares, tais trabalhos envolvem subjetividades negativas e limitações físicas do/a outro/a, requerendo um alto grau de interiorização do afeto ou uma gestão das emoções (HOCHSCHILD, 1983). Nesse terreno frágil para todas as partes envolvidas, a confiança e a solidariedade se tornam o liame necessário na concretização do cuidado (Damamme, Soares). Arango traz uma nova noção na literatura, a do "cuidado reparador”, que age para superar o sofrimento das vítimas do racismo no contexto do serviço estético, junto a pessoas negras em salões de beleza especializados. Em outro caso, é apresentada a mobilização social para o reconhecimento das necessidades do/as destinatários/as do cuidado, principalmente quando se refere a atenção a longo prazo, como às crianças com deficiência física e/ou mental (Damamme). Em ambos os casos, trata-se de uma luta pela cidadania de grupos longamente estigmatizados.

O horizonte das mobilizações coletivas leva outros/as autores/as a se posicionarem sobre o papel do Estado no cuidado. Podemos afirmar que no Brasil a perspectiva politizada e setorizada que responde às necessidades específicas de segmentos em desvantagem, como mulheres e idosos (Bessin, Sorj e Debert), é relativamente nova, pois a reflexão sobre os serviços de cuidado ofertados pelo Estado e suas imbricações para os/as trabalhadores/as e os/as usuários/as tem surgido dentro de uma discussão em que as políticas sociais foram se consolidando ao longo dos trinta anos enquanto direito, tendo como marco a adoção da Constituição de 1988. O espaço privado tem se tornado um lugar legítimo de intervenção do Estado (LASCH, 2014) e a política da presença um novo dispositivo da "gestão da pobreza" (SPOSATI, 1988). As mulheres, principalmente as pobres, são focalizadas enquanto mediadoras na efetivação dessas políticas (JENSON, 2011; GEORGES; SANTOS, 2016, além de Sorj, no livro). No sentido de superar uma mera administração do social a partir de uma visão dos privilegiados, Bessin enfatiza a importância de se compreender uma temporalidade distinta que guia (principalmente) as atrizes do cuidado. 


\section{REFERÊNCIAS}

BLAY, Eva. Trabalho domesticado: a mulher na indústria paulista. São Paulo: Ática, 1978.

BRUSCHINI, Maria Cristina Aranha. Trabalho e gênero no Brasil nos últimos dez anos. Cadernos de Pesquisa, São Paulo, v. 37, n. 132, p. 537-572, set./dez. 2007.

CASTRO, Mary. O conceito de gênero e as análises sobre mulher e trabalho: notas sobre impasses teóricos. Caderno CRH, Salvador, n. 17, p. 80-105, 1992.

CASTRO, Mary; LAVINAS, Lena. Do feminino ao gênero: a construção de um objeto. In: COSTA, A.; BRUSCHINI, C. (Org.). Uma questão de gênero. Rio de Janeiro: Rosa dos Tempos, 1992. p. 216-251.

COSTA, Albertina; BARROSO, Carmen; SARTI, Cynthia. Pesquisa sobre mulher no Brasil: do limbo ao gueto. Cadernos de Pesquisa, São Paulo, n 54, p. 5-15, ago. 1985.

CRENSHAW, Kimberlé. Demarginalizing the intersection of race and sex: a black feminist critique of antidiscrimination doctrine, feminist theory and antiracist politics. University of Chicago Legal Forum, Chicago, v. 1989, n. 1, p. 139-167, 1989.

CRENSHAW, Kimberlé. Mapping the margins: intersectionality, identity politics, and violence against women of color. Stanford Law Review, v. 43, n. 6, p. 1241-1299, Jul. 1991.

ELIAS, Norbert; SCOTSON, John L. Os estabelecidos e os outsiders: sociologia das relações de poder a partir de uma pequena comunidade. Rio de Janeiro: Zahar, 2000.

GEORGES, Isabel; SANTOS, Yumi Garcia dos. As novas políticas sociais brasileiras na saúde e na assistência. Produção local do serviço e relações de gênero. Belo Horizonte: Fino Traço, 2016.

HEILBORN, Maria Luiza; SORJ, Bila. Estudos de gênero no Brasil. In: MICELI, S. (Org.). o que ler na ciência social brasileira (1970-1995). São Paulo: Sumaré, 1999. p. 183-221.

HIRATA, Helena; KERGOAT, Danièle. Novas configurações da divisão sexual do trabalho. Cadernos de Pesquisa, São Paulo, v. 37, n. 132, p. 595-609, set./dez. 2007.

HOCHSCHILD, Arlie. The managed heart: Commercialization of human feeling. Berkeley: University of California Press, 1983.

HOCHSCHILD, Arlie; EHRENREICH, Barbara (Ed.). Global women: nannies, maids, and sex workers in the new economy. New York: Owl Books, 2004.

JENSON, Jane. Politiques publiques et investissement social: quelles conséquences pour la citoyenneté sociale des femmes? In: MARQUES-PEREIRA, B.; PFEFFERKORN, R. (Coord.). Genre, politiques sociales et citoyenneté. Paris: L'Harmattan, 2011. p. 21-43. (Cahiers du Genre)

KERGOAT, Danièle. O cuidado e as imbricações das relações sociais. In: ABREU, Alice Rangel de Paiva; HIRATA, Helena; LOMBARDI, Maria Rosa (Org.). Gênero e trabalho no Brasil e na França: perspectivas interseccionais. São Paulo: Boitempo, 2016. p. 17-26.

LASCH, Carolina Rojas. Sexuación y subjetivación en las prácticas de asistencia en Chile. Cadernos de Pesquisa, São Paulo, v. 44, n. 152, p. 312-333, abr.jjun. 2014.

SAFFIOTI, Heleieth I. B. A mulher na sociedade de classes: mito e realidade. Petrópolis: Vozes, 1976. SOUZA-LOBO, Elisabeth. A classe operária tem dois sexos: trabalho, dominação e resistência. São Paulo: Fundação Perseu Abramo, 2011.

SPOSATI, Aldaíza. Vida urbana e gestão da pobreza. São Paulo: Cortez, 1988.

\section{YUMI GARCIA DOS SANTOS}

Professora do Departamento de Sociologia da Universidade Federal de Minas Gerais - UFMG -, Belo Horizonte, Minas Gerais, Brasil yumigds@uol.com.br 